\title{
Using The Internet To Communicate Environmental Sustainability Issues To Stakeholders: An Italian Perspective
}

Peter A. Stanwick, Auburn University

Sarah D. Stanwick, Auburn University

\begin{abstract}
This study examined how Italian firms use information technology to communicate with stakeholders. The results of the study indicate that a majority of the firms in the sample communicated traditional sustainability disclosures. The communication of transformational and proactive sustainability disclosures were based, in part, on the financial performance level of the firms. The study also found that Italian firms had similar disclosure patterns to firms from other countries.
\end{abstract}

\section{INTRODUCTION}

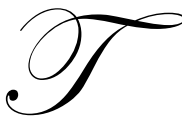

he purpose of this article is to examine how corporations use information technology in order to communicate issues related to environmental sustainability to their stakeholders. With the introduction of "real time" communication between firms and individuals via the internet, this advancement in technology has open up endless opportunities for firms to communicate their actions to individuals that are interested in their operations, often called stakeholders.

\section{STAKEHOLDER THEORY}

The underlying philosophy of stakeholder theory was actually established during the great depression. A. A. Berle wrote in the Harvard Law Review in 1931 that corporations should use their power to aid and contribute to the interest of all the company's stakeholders. A stakeholder can be defined as any group that has a vested interest in the day to day operations of the firm. Common stakeholders include: stockholders, customers, employees, suppliers, governments, local communities, and society as a whole. Edward Freeman extended the work of Berle in 1984 by presenting a comprehensive analysis of the impact stakeholders have on the operations of a firm. Freedman argued that stakeholder theory presents a reciprocal relationship between the firm and stakeholders. The firm has an impact on the stakeholders and the stakeholders also have an impact on the firm.

With the introduction of the Internet into the day to day operations of both firms and stakeholders, firms have a valuable opportunity to communicate directly to their stakeholders via electronic communications. The Internet has allowed firms to present the positive aspects of their operations and has also allowed stakeholders to obtain more information in order to monitor and evaluate their operations.

\section{USING THE INTERNET TO COMMUNICATE ENVIRONMENTAL SUSTAINABILITY}

One of the critical areas in which all stakeholders have a vested interest is in how firms address issues pertaining to the natural environment. By capturing an Academy Award and sharing in the 2007 Nobel Peace prize, Al Gore has highlighted the urgency for both stakeholders and firms to address issues related to the long term sustainability of the earth's environment. As a result, the content of the environmental disclosures posted on a firm's web site, presents information in order for all stakeholders to develop an informed opinion the type and comprehensiveness as it relates to the firm's commitment to the natural environment (Stray and Galantine, 2000). 


\section{THE ROLE OF ENVIRONMENTAL DISCLOSURES FROM AN INTERNATIONAL PERSPECTIVE}

Previous research has shown that having a comprehensive level of environmental disclosures may have a positive impact on the firm since it could aid in the development of a firm's competitive advantage (Bullough and Johnson, 1995; Dechant and Altman, 1994; Porter and van der Linde, 1995). However, a significant limitation of previous research is that the majority of studies focus on either American or British firms. Although disclosures from other countries have been examined in the past including Canadian, German and French firms (Cormier, Gordon, Magnan, 2004), a comprehensive review of Italian firms has not taken place.

\section{HYPOTHESIS DEVELOPMENT}

It is expected that the firms in the same industry would have the same objectives of serving the needs of its stakeholders through information technology. As a result, disclosing sustainability information should generate a positive impact for serving the needs of the stakeholders since the stakeholders are interested in information pertaining to the firm's commitment to sustainability. Furthermore, it is expected that a majority of the firms would at least address the traditional sustainability issues facing the firm. Traditional disclosures address issues that have a long standing history by focusing on various stakeholders and these disclosures are usually the first issues that a firm addresses pertaining to sustainability. Therefore hypothesis 1 is:

H1: A majority of the firms in all financial performance levels would address traditional sustainability issues.

The firms were separated into three categories based on their financial performance. The financial performance of the firms was calculated based on the ratio of the firm's profits and the firm's revenues. Based on that calculation, ten firms were then classified as either high financial performers, medium financial performers or low financial performers. (Stanwick and Stanwick, 2000).

The second category of disclosures was called transformational disclosures. This type of disclosure moves beyond the legal disclosures which are represented in the traditional category. Transformational disclosures are the firm's signal to its stakeholders that it is moving towards a more proactive commitment to sustainability. The third category of disclosures was called proactive disclosures. These types of disclosures identify firms that are at the forefront in their sustainability commitment. Based on previous research that has shown that firms that are proactive in addressing sustainability issues could benefit their financial performance (Porter and van der Linde 1995), it is expected that firms that address transformation and proactive disclosures could be using these issues to help enhance their competitive advantage. Furthermore, the results of the study by Stanwick and Stanwick (2000) highlighted that firms in the medium financial performance category may have the highest levels of these types of disclosures since they could be more aggressive in trying to improve their financial performance. Therefore, hypotheses 2 and 3 are:

H2: Firms with a medium level of financial performance will have the highest incidences of transformational sustainability disclosures.

H3: Firms with a medium level of financial performance will have the highest incidences of proactive sustainability disclosures.

\section{METHODOLOGY}

Thirty Italian firms were randomly selected from sustainability reports that were available at CorporateRegister.com. CorporateRegister.com is the world's largest online directory of corporate reports that address non financial issues. The criteria to be included in the sample were that the sustainability report must have been released in 2006 and contained data from 2005. In addition, the report must be printed in English so that the authors could interpret the content of the report. After the 30 firms had been identified, a content analysis was done for each report. The content of the report was classified into 18 major categories, grouped into three major classifications. The classifications are based on type of issues that are addressed in the 17 categories. There are seven categories which are grouped together into the traditional category. Those seven categories were: water 
reduction-pollution, energy reduction-pollution, waste management-recycling, air pollution, employee training, specific environmental goals, and having an environmental policy. There were five types of disclosures in the transformational category which included: using eco-friendly raw materials and producing eco-friendly final products, reduction in transportation impacts, sustainability audits, using Environmental Management Systems (EMS), addressing specific community needs pertaining to sustainability. There were five types of disclosures in the proactive category which were: focusing on renewable energy alternatives, reducing noise pollution, biodiversity (the interconnection between different life forms within an ecosystem), referring the Kyoto protocol (a treaty signed by industrialized nations to voluntarily reduce the level of Greenhouse Gas emissions) and identifying specific actions related to the reduction of (GHG) emissions.

\section{RESULTS}

The data for the study has yielded some interesting results (See Table 1). The first hypothesis stated that a majority of all the firms in the sample would address traditional sustainability issues. The results support Hypothesis 1. For each of the seven traditional sustainability disclosures categories, over fifty percent of the firms in the sample addressed each of the seven issues. Of the thirty firms in the sample, 23 (76.67\%) addressed water reduction, 28 (93.33\%) addressed energy reduction, 28 (93.33\%) addressed waste management, 17 (56.67\%) addressed air reduction, $16(53.33 \%)$ addressed environmental training, 24 (80\%) identified specific environmental goals and 24 $(80 \%)$ had a specific environmental policy.

Hypothesis two stated that firms with a medium level of financial performance would have the highest incidences of transformational sustainability disclosures. The results shown in Table one do not support this hypothesis. The results showed that the low performing firms had the highest level of transformational sustainability. The results also showed that the high performing firms had the lowest level of transformational disclosures. Hypothesis three stated that firms with a medium financial performance would have the highest incidences of proactive sustainability disclosures. The results in Table one support this Hypothesis. Firms with the medium financial performance had the highest incidences of proactive sustainability disclosures while firms with the lowest level of financial performance had the lowest level of proactive sustainability disclosures.

\section{CONCLUSIONS}

There are a number of important conclusions based on the results of this study. The data from the study supports the view that firms are using information technology to ensure that their stakeholders are better informed pertaining to sustainability issues. In addition, the results show that Italian firms follow a similar pattern to American firms pertaining to the type of sustainability disclosures that are presented electronically for stakeholders to read.

The results supported Hypothesis one which stated that a majority of the firms would discuss traditional sustainability issues. However, it is interesting to note the significant range in the total number of issues that were disclosed. Both issues pertaining to energy reduction and waste management were well represented within 28 of the 30 firms discussing these issues. Alternatively, environmental training was also disclosed by only 16 of the 30 firms. This discrepancy could be due to the fact that it may be easier to present a cost benefit analysis for energy and waste reduction as compared with measuring the tangible results of an environmental training program.

The results of the study did not support Hypothesis two. In fact, low performing firms rather than medium performing firms had the most transformational sustainability disclosures. This extends research in the area by identifying that not only medium performing firms but also low performing firms develop sustainability disclosures to enhance their competitive advantage. It is also interesting to note the significantly lower number of transformational sustainability disclosures (63) as compared with traditional sustainability disclosures (160). This highlights the shift from addressing legal based sustainability issues and moving toward more voluntary and proactive sustainability issues. 
Hypothesis three was supported based on the results of the study. By a large margin, medium performing firms had the highest level of proactive sustainability disclosures. This also extends the current research in this area. It could be interpreted based on the results shown for the transformational and proactive sustainability disclosures that low performing firms are moving toward a transformational sustainability strategy while medium performing firms have already addressed the issues of transformational sustainability strategies and have moved forward in developing proactive sustainability strategies. Therefore, the results show that the gradual developed of firms based on their financial performance. Low performing firms must first address transformational issues which could lead to increased financial performance and then the companies move toward proactive sustainability strategies in order to try to further increase their financial performance.

\section{SUMMARY}

In summary, the results of this study show that firms use information technology in order to communicate with their stakeholders. In addition, Italian firms have similar patterns of sustainability disclosures as compared to firms from other countries. Finally, most first address traditional sustainability issues while the shifting toward transformational and proactive sustainability issues may be used to enhance a firm's competitive advantage to help them improve their financial performance.

Table 1

Results of the Study

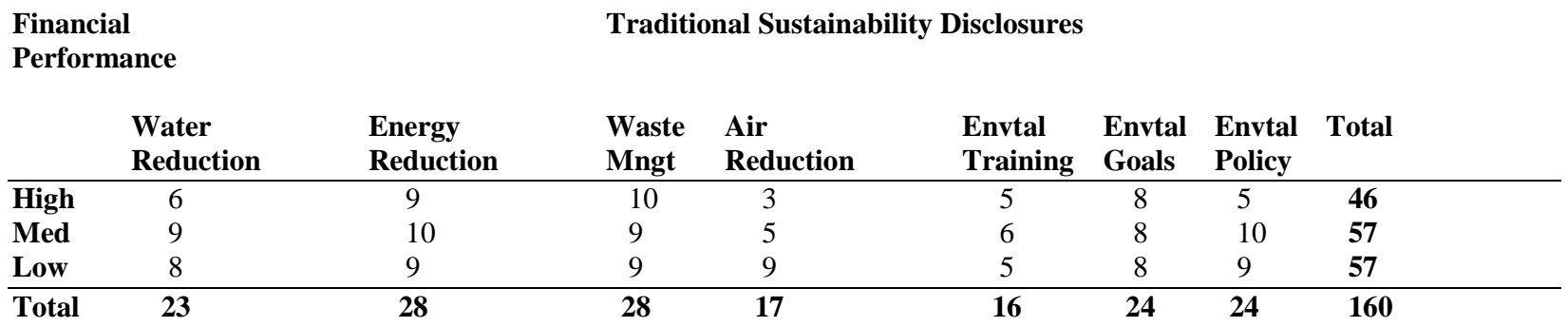

Financial

Transformational Sustainability Disclosures

Performance

\begin{tabular}{lcccccc} 
& $\begin{array}{l}\text { Eco-Raw } \\
\text { Materials/Products }\end{array}$ & Transportation & $\begin{array}{l}\text { Envtal } \\
\text { Audit }\end{array}$ & EMS & Community & Total \\
\hline High & 1 & 6 & 1 & 5 & 3 & 16 \\
Med & 6 & 5 & 2 & 9 & 1 & 23 \\
Low & 6 & 5 & 2 & 8 & 3 & 24 \\
\hline Total & $\mathbf{1 3}$ & $\mathbf{1 6}$ & $\mathbf{5}$ & $\mathbf{2 2}$ & $\mathbf{7}$ & $\mathbf{6 3}$
\end{tabular}

Financial

Proactive Sustainability Disclosures

Performance

\begin{tabular}{lcccccc} 
& $\begin{array}{l}\text { Renewable } \\
\text { Energy }\end{array}$ & $\begin{array}{l}\text { Noise } \\
\text { Pollution }\end{array}$ & Biodiversity & $\begin{array}{l}\text { Kyoto } \\
\text { Protocol }\end{array}$ & $\begin{array}{l}\text { GHG } \\
\text { Emissions }\end{array}$ & Total \\
\hline High & 4 & 4 & 1 & 3 & 6 & 18 \\
Med & 6 & 6 & 4 & 6 & 10 & 32 \\
Low & 3 & 1 & 1 & 3 & 6 & 14 \\
\hline Total & $\mathbf{1 3}$ & $\mathbf{1 1}$ & $\mathbf{6}$ & $\mathbf{1 2}$ & $\mathbf{2 2}$ & $\mathbf{6 4}$
\end{tabular}




\section{REFERENCES}

1. $\quad$ Berle, A. A.. 1931. Corporate Powers as Powers in Trust, Harvard Law Review. 44.

2. Bullough M., and D. Johnson. 1995. Corporate Environmental Reporting in Practice. Business Strategy and the Environment 4:36-39.

3. Cormier, D., I. Gordon, and M. Magnan. 2004. Corporate Environmental Disclosure: Contrasting Management's Perceptions with Reality. Journal of Business Ethics 49:143-165.

4. Dechant, K. and B. Altman. 1994. Environmental Leadership: From Compliance to Competitive Advantage. Academy of Management Executive 8:7-27.

5. $\quad$ Freeman, R. E.. 1984. Strategic Management: A Stakeholder Approach (Boston: Pitman).

6. Porter, M. and C. van der Linde. 1995. Green and Competitive: Ending the Stalemate. Harvard Business Review 73:120-134.

7. Stanwick, S. and P. Stanwick. 2000. The Relationship Between Environmental Disclosures and Financial Performance: An Empirical Study of US Firms. Eco-Management and Auditing 7:155-164.

8. Stray, S. and J. Galantine. 2000. A Sectoral Comparison of Corporate Environmental Reporting and Disclosure. Eco-Management and Auditing 7:165-177.

\section{NOTES}


NOTES 